\title{
A Theory of Extramarital Affairs
}

\section{Ray C. Fair}

Yale University

In this paper a model is developed that cxplains the allocation of an individual's time among work and two types of leisure activities: time spent with spouse, and time spent with paramour. Data from two recent magazine surveys are available that can be used to test the predictions of the model regarding the determinants of time spent with paramour. The results of estimating the equation explaining time spent with paramour, by the Tobit estimator, are generally supportive of the model, although more evidence is needed before any definitive conclusions can be drawn. The model can also be applied to the allocation of time among other types of leisure activities.

\section{Introduction}

Relationships with other people are generally an important part of a person's life. The key relationship for most adults is, of course, that with one's spouse and children. The fact that most adults are married and have children has undoubtedly been an important reason for the emphasis in the literature on the household as a basic decision unit. Becausc of this emphasis, little consideration has been given to the question of the allocation of a person's leisure time ${ }^{1}$ between activities with household members and activities with nonhousehold members. Even Becker's (1973) pioneering work on marriage, which as he points out (p. 816) does not require that different members of the household have the same preference function, concentrates on the allocation of a person's time betwcen time spent

I would like to thank Sharon Oster for many helpful comments on this paper. I am also indebted to Gcorge Stigler and an anonymous referee for useful suggesions, to the editors of Psychalogy Today and Redbook for permission to use data from two recent surveys, and to Robert Athanasiou, Shirley Glass, and Susan Sadd for help in supplying me with the data. 1 assume responsibility for all errors.

${ }^{1}$ By "leisure time" in this paper is meant any time spent in nonmarket activities. 
in household activities and time spent in market activities. For many people, leisure time spent with nonhousehold members plays an important role in their lives, and it is unfortunate that this fact has received so little attention by economists.

The purpose of this paper is to consider the determinants of leisure time spent in one particular type of activity with nonhousehold members: extramarital affairs. 'The extent of such activity is by no means small. In one of the two surveys used for the empirical work in this study, 27.2 percent of the first-time-married working men and 22.9 percent of the firsttime-married working women wcre having an extramarital affair at the time of the survey. In the other survey (of women only), 32.2 percent of the first-time-married working women had had at lcast one affair during their married lives. Given the apparent frequency of extramarital affairs, it is of some interest to see if economic analysis can help to predict their incidence.

In Section II a theoretical model is presented that explains the allocation of a married person's timc among work, spouse, and paramour. Time spent with paramour is seen to be a function of the person's wage rate, the price lcvel, the pcrson's nonlabor income, the time spent by the spouse in the marriage, the value of goods supplied by the spouse to the marriage, the time spent by the paramour in the affair, the value of goods supplied by the paramour to the affair, and any other variables that have an effect on the utility received from the marriage or on the utility received from the affair.

Some data are available from two recent magazine survcys, conducted respectively by $P_{s y c h o l o g y}$ Today and Redbook, that can be used to test the model. The variables that were constructed from these surveys for use in this study are discusscd in Section III. The results of estimating the model, by the Tobit estimator (Tobin 1958), are presented and discussed in Section IV. Although the data are far from ideal for testing the model, the results presented in Section IV are generally supportive of it. The results clearly appear to be good enough to warrant further tests of the model in the future if more data become available.

Although the theoretical model developed in the next section is concerned with two specific types of leisure activities, time spent with spouse and time spent with paramour, it should be fairly clear that the model has wider applicability than this. Many types of leisure activities with nonhousehold members are covered by the theory. Participation in a men's club or a women's auxiliary, for example, is clearly a type of leisure activity that is covered by the theory; the theory is not limited merely to sexual activities. The model in the next section could have been formulated in more general terms first and then applied to the extramarital affairs case, but there seemed little point in doing this. The model is easier to present by means of a particular case, and once presented in this way it can be applied easily to other cases. 


\section{The Theoretical Model}

The primary motivation for the model is the idea that people like variety in their lives. This idea is hardly novel in economics, since it is presumably one of the main motivations for the inclusion of more than one type of good in the utility function in classical demand theory. This same idea has not, however, generally been applied to leisure activities-in particular, for present purposes, to lcisure activities with different people. All leisure activities are generally grouped together into one variable called "leisure."

Outside of economics it is easy to find defenses for the idea that variety is important in people's lives. They range from the cliche, "variety is the spice of life," to the poetry of John Donne (1967 ed.):

The heavens rejoyce in motion, why should I

Abjure my so much lov'd variety,

And not with many youth and love divide?

Pleasure is none, if not diversifi'd.

Since it is clear that variety is important in life, and since this idea is already one of the main motivations for the inclusion of more than one good in the utility function, there is ample justification for applying it to leisure activities. This will now be done for two particular types of leisure activities.

Consider a married individual $i$ and assume that there are three types of activities that he or she can engage in: time spent with spouse $\left(t_{1}\right)$, with paramour $\left(t_{2}\right)$, and working $\left(t_{3}\right)$. Let $U_{1}$ and $U_{2}$ denote the utility that $i$ derives from the spouse and paramour relationships, respectively. Variety with respect to relationships is assumed to be important to $i$, and, as mentioned above, this is the main justification for postulating more than one type of relationship. For simplicity, there is assumed to be only one possible paramour and only one type of good in existence. This latter assumption means that variety with respect to goods is ruled out of the analysis, an omission that is of little consequence for purposes of the present study.

Now, $U_{1}$ is postulated to be a function of $t_{1}$, of the time spent by the spouse in the relationship $\left(t_{s}\right)$, of the number of units of the good consumed in the relationship $\left(x_{1}\right)$, and of a vector of other variables $\left(E_{1}\right)$ :

$$
U_{1}=f\left(t_{1}, t_{s}, x_{1}, E_{1}\right)
$$

The vector $E_{1}$ is taken to include all variables that have an effect on $U_{1}$ other than $t_{1}, t_{s}$, and $x_{1}$. The function $f$ is similar to what Becker (1973) calls the household production function. Variables such as the times spent by the children in the household, which are included in Becker's household production function, are assumed here to be included in $E_{1}$. 
Similarly, $U_{2}$ is postulated to be a function of $t_{2}$, of the time spent by the paramour in the affair $\left(t_{p}\right)$, of the number of units of the good consumed in the affair $\left(x_{2}\right)$, and of a vector of other variables $\left(E_{2}\right)$ :

$$
U_{2}=g\left(t_{2}, t_{p}, x_{2}, E_{2}\right) \text {. }
$$

The vector $E_{2}$ is taken to include all variables that have an effect on $U_{2}$ other than $t_{2}, t_{p}$, and $x_{2}$.

The total utility of $i(U)$ is postulated to be the sum of $U_{1}$ and $U_{2}$ :

$$
U=U_{1}+U_{2} \text {. }
$$

The functions $f$ and $g$ are assumed to be strictly concave.

The variable $x_{1}$ consists of units of the good supplied by $i\left\langle x_{1 i}\right\rangle$ and of units of the good supplied by the spouse $\left(x_{1 s}\right)$ :

$$
x_{1}=x_{1 \imath}+x_{1 s} .
$$

Similarly, $x_{2}$ consists of units of the good supplied by $i\left(x_{2 i}\right)$ and of units of the good supplied by the paramour $\left(x_{2 p}\right)$ :

$$
x_{2}=x_{2 i}+x_{2 p}
$$

$t_{1}, t_{2}$, and $t_{3}$ are assumed to sum to the total available time in the period $(T)$ :

$$
T=t_{1}+t_{2}+t_{3} .
$$

The decision problem for $i$ is to choose $t_{1}, t_{2}, x_{1 i}$, and $x_{2 i}$ so as to maximize $U$, subject to the budget constraint:

$$
w\left(T-t_{1}-t_{2}\right)+V=p\left(x_{1 i}+x_{2 i}\right)
$$

where $p$ is the price of the good, $w$ is $i$ 's wage rate, and $V$ is $i$ 's nonlabor income. The problem is also restricted in that $t_{1}, t_{2}, x_{1 i}$, and $x_{2 i}$ cannot be negative. Taken as given for purposes of this problem are $t_{s}, t_{p}, x_{1 s}, x_{2 p}$, $p, w, V, E_{1}$, and $E_{2}$. Note that the budget constraint (7) is not the household budget constraint but is rather $i$ 's individual budget constraint. The decision problem analyzed here is an individual decision problem, not a household decision problem. Note also that the treatment of $t_{s}$ and $x_{1 s}$ as exogenous means that no consideration is given to possible effects of $i$ 's decisions on the spouse's decisions. ${ }^{2}$ Likewise, the treatment of $t_{p}$ and $x_{2 p}$

2 The assumption that $t_{\mathrm{s}}$ and $x_{\mathrm{s}}$ are exogenous is clearly a strong one in the present context, and, as mentioned below, it might be of interest in future work to relax it. If the spouse is unaware of $i$ 's affair, then the assumption is, of course, less restrictive than otherwise. The assumption would also be less restrictive if the other leisure activity were something like participation in a club or auxiliary. It should also be noted that the model could be easily modified to the case in which the paramour is a prostitute. In this case $t_{p}$ would be purchased by $i$ at some rate $w_{p} ; t_{p}$ would now be a decision variable for $i$, rather than being exogenous, and $w_{p}$ would be exogenous. The budget constraint in this case would be: $w\left(T-t_{1}-t_{2}\right)+V=p\left(x_{1 i}+x_{2 i}\right)+w_{p} t_{p}$. 
as exogenous means that no consideration is given to possible effects of $i$ 's decisions on the paramour's decisions.

The decision problem for $i$ can be solved in the standard way by setting up the Lagrangian,

$$
\mathscr{L}=U+\lambda\left[w\left(T-t_{1}-t_{2}\right)+V-p\left(x_{1 i}+x_{2 i}\right)\right],
$$

and differentiating $\mathscr{L}$ with respect to the four decision variables and $\lambda$. The first-order conditions are:

$$
\begin{gathered}
\frac{\partial f}{\partial t_{1}}-\lambda w=0, \\
\frac{\partial g}{\partial t_{2}}-\lambda w=0, \\
\frac{\partial f}{\partial x_{1 i}}-\lambda p=0 \\
\frac{\partial g}{\partial x_{2 i}}-\lambda p=0, \\
w\left(T-t_{1}-t_{2}\right)+V-p\left(x_{1 i}+x_{2 i}\right)=0 .
\end{gathered}
$$

These conditions hold if the solution is an interior one; they do not necessarily hold if, for example, the optimum value of $t_{2}$ is zero. For purposes of the rest of the discussion in this section, however, the solution is assumed to be an interior one.

The first-order conditions can be interpreted in the usual way. At the optimum, the marginal utility of time spent in the marriage is equal to the marginal utility of time spent in the affair $\left(\partial f / \partial t_{1}=\partial g / \partial t_{2}\right)$. Similarly, the marginal utility of consumption of the good in the marriage is equal to the marginal utility of consumption of the good in the affair $\left(\partial f / \partial x_{1 i}=\right.$ $\partial g\left(\hat{\partial} x_{2 i}\right)$. Finally, the marginal rate of substitution between time spent in the marriage (affair) and consumption of the good in the marriage (affair) is equal to the real wage $\left(\partial f / \partial t_{1} \div \partial f / \partial x_{1 i}=w / p\right.$ and $\partial g / \partial l_{2} \div$ $\partial g / \partial x_{2 i}=w(p)$.

The main concern of this paper is to trace the effects of changes in the various exogenous variables on $t_{2}$. This can be done by taking the total derivatives of equations (9a)-(9e) and then solving, using Cramer's Rule, for the derivative of $t_{2}$ with respect to each exogenous variable (all other exogenous variables assumed to remain unchanged). The results from this exercise will now be summarized. The following discussion of signs is based on the assumption that all first derivatives of $f$ and $g$ are positive, that all cross partial derivatives of $f$ and $g$ are positive, and that all second derivatives of $f$ and $g$ are negative. 
The determinant of the bordered Hessian is positive because of the strict concavity of $f$ and $g$. The following derivatives relating to $t_{2}$ are unambiguous in sign:

$$
\frac{d t_{2}}{d V}>0 ; \frac{d t_{2}}{d x_{1 s}}=\frac{d t_{2}}{d x_{2 p}}=p \frac{d t_{2}}{d V}>0 ; \frac{d t_{2}}{d t_{s}}<0 ; \frac{d t_{2}}{d E_{1}}<0 .
$$

The first term is the income effect on $t_{2}$; it is positive as expected. An increase in $V, i$ 's nonlabor income, causes $i$ to work less and to increase both $t_{1}$ and $t_{2}\left(d t_{1} / d V\right.$ is also positive $)$. The next two derivatives in (10) are, respectively, the eflect on $t_{2}$ of a change in units of the good supplicd by the spouse to the marriage and by the paramour to the affair. Both derivatives are equal to the price of the good times the income effect. Since there are no restrictions on the allocation of units of the good that $i$ purchases between the marriage and the affair, an increase in $x_{1 s}$ or $x_{2 p}$ has the same effect as an equivalent increase in $i$ 's nonlabor income, which is in this case merely the price of the good times the increase in $x_{1 s}$ or $x_{2 p}$. (An increase in $x_{1 s}$ or $x_{2 p}$ also has a positive effect on $t_{1}$, the effect being $p$ times $d t_{1} / d V$.)

The second-to-last derivative in (10) is the effect on $t_{2}$ of a change in the time spent by the spouse in the marriage. The effect is negative. If the spouse spends more time in the marriage, this increases the utility that $i$ derives from the marriage and causes the time spent in the affair to fall. This negative effect of the spouse on $t_{2}$ is to be contrasted with the effect on $t_{2}$ of an increase in units of the good supplied by the spouse to the marriage, which, as just discussed, is equivalent to an income effect and is positive. The last derivative in (10) is the effect on $t_{2}$ of a change in $E_{1}$, any variable that has a positive effect on the utility from the marriage. This effect is negative as expected.

The following derivatives relating to $t_{2}$ are ambiguous in sign:

$$
\frac{d t_{2}}{d w} ; \frac{d t_{2}}{d p} ; \frac{d t_{2}}{d t_{p}} ; \frac{d t_{2}}{d E_{2}}
$$

The ambiguity of the wage and price effects comes from the usual ambiguity due to income and substitution effects. The income effect of an increase in $w$ on $t_{2}$ is positive, and the substitution effect is negative. Conversely, the income effect of an increase in $p$ on $t_{2}$ is negative, and the substitution effect is positive.

Consider now the third term in (11), the effect on $t_{2}$ of a change in the time spent by the paramour in the affair. An increase in $t_{p}$ increases the utility that $i$ derives from the affair, which leads, other things being equal, to an increase in $t_{2}$. An increase in $t_{p}$ also, however, affects the division of $i$ 's time between work and leisure, and it is from this effect that the ambiguity in the sign of $d t_{2} / d t_{p}$ arises. In particular, an increase in $t_{p}$ increases the marginal utility that $i$ derives from consuming the good in the affair. 
This, other things being equal, induces some increase in working time. If this effect of a decrease in leisure time is very large, it may swamp the substitution effect and cause an ovcrall fall in $t_{2}$. In most cases, this seems unlikely, so in general it is likely that $d t_{2} / d t_{p}$ is positive. A similar argument holds for $d t_{2} / d E_{2}$; in general it is likely to be positive.

This completes the presentation of the formal model. A summary of it is presented in the first half of table 2. Before concluding this section, however, mention should be made of other ways that one might model behavior concerning extramarital affairs. One way would be to borrow from the literature on the economics of crime (see, e.g., Becker 1968) and consider the decision on whether or not to have an affair to be analogous to the decision on whether or not to commit a crime. The individual in making the decision would weigh the gains from the affair against the expected loss, where the expected loss is the probability of being caught times the cost if caught. In this framework one would consider the factors that influence the gain from the affair, the factors that influence the probability of getting caught, and the factors that influence the cost if caught.

A second way would be to set the decision problem up as a multiperiod optimization problem, where cach period the individual would choose paths of the decision variables. The range of the paths would be from the initial period (the period in which the decision was made) to the end of the person's life. This treatment would allow one to consider in an explicit way the effects of future events (or expected future events) on current decisions. A third approach would be to drop the assumption that $i$ 's decisions have no effect on the spouse's decisions, and either set up the problem as a game-theory problem or else postulate explicitly how i's decisions affect the spouse's decisions. Finally, one might borrow from the job-search literature, and interpret extramarital affairs as a form of search for an alternative spouse. Many of the same types of factors that induce a worker to search for an alternative job could be postulated as inducing a person to search for an alternative spouse. ${ }^{3}$ In future work it may be of interest to pursue one or more of these approaches, but for purposes of this paper the analysis is limited to the above model.

${ }^{3}$ Much of the theory in Kelley (1976) can be interpreted as a theory of search for a spouse. Kelley's theory implies (p. 22) that, other things being equal, length of marriage should have a negative effect on time spent in extramarital affairs (search for an alternative spouse). This implication is consistent with the theory of job search, where search for an alternative job is a negative function of the length of the present job. The empirical results reported in Scction IV of this paper arc, however, contrary to this conclusion: length of marriage has a positive effect on time spent in extramarital affairs. It is somewhat unclear whether Kelley's theory can be modified to fit this result or not. In this paper the result is interpreted to mean that utility from marriage declines with length of marriage. Kelley's discussion (pp. 23-24) of the effects of income on time spent in extramarital affairs is not very convincing because he does not appear to be aware of the difference between income and substitution effects. 


\section{The Data and Estimation Technique}

It is possible from two recent magazine surveys to gather data that can be used to estimate the above model. As with a lot of data, they are not the best that one might hope for, but they do appear to be at least of some use for present purposes. The first survcy was conducted in 1969 by Psychology Today (PT). A questionnaire on sex was published in the July 1969 issue of $P T$, and readers were asked to mail in their answers. About 20,000 replies were received, of which about 2,000 were coded onto tape. The second survey, of women only, was conducted in 1974 by Redbook $(R B)$. A questionnaire on sex was published in the October issue of $R B$, and readers were asked to mail in their answers. About 100,000 replies were received, of which about 18,000 were coded onto tape. The questionnaires included questions about extramarital affairs as well as about many other aspects of sexual behavior and about various demographic and economic characteristics of the individual. The $P T$ and $R B$ questionnaires included 101 and 81 questions, respectively. The discussion of the answers to the $P T$ survey can be found in the July 1970 issue of $P T$.

It should be noted that neither of these two surveys is likely to be a random sample of the U.S. population. For present purposes, of course, a random sample is unnecessary. What is needed here is the condition that the samples have not been selected on the basis of the size of the dependent variables used in the estimation work, that is, on the basis of the amount of time spent in extramarital affairs. Although this requirement is much less strong than the requirement that the sample be random, there is no guarantee that it is met in the present case. There may thus be some bias in the following results due to the sampling procedure, although, at least to the author, this bias does not seem likely to be very large.

Table 1 contains a list of the variables that were constructed from the data on the two tapes. Only people who were married and married for the first time were included in the sample from each tape. People who were married but married more than once were excluded because of lack of information on some of the variables for these people. The questions regarding the number of years married and the number or existence of children, for example, pertain to all marriages, and it is not possible if a person has been married more than once to determine the length of the current marriage and the number or existence of children from the current marriage. Also, only employed people were included in the sample from each tape. For unemployed people, $t_{3}$ in the above model is zero, and the solutions to their maximization problems are not interior ones. The firstorder conditions, therefore, do not necessarily hold for unemployed people, and so these people must be excluded from the samples. Also excluded from the samples were people who failed to answer all the relevant questions. The size of the usable sample from the $P T$ tape was 601 obser- 
TABLE 1

Variables Constructed from the Data on the $P T$ and $R B$ Tapes

\begin{tabular}{|c|c|c|c|c|}
\hline $\begin{array}{c}\text { Question } \\
\text { No. }\end{array}$ & $\begin{array}{l}\text { Notation } \\
\text { for } \\
\text { Variable }\end{array}$ & $\begin{array}{l}\text { Description } \\
\text { of Variable }\end{array}$ & Values of Variable & $\begin{array}{l}\text { Mean } \\
\text { Value }\end{array}$ \\
\hline & \multicolumn{4}{|c|}{$P T$ Tape } \\
\hline $75 \ldots$ & $y_{P T}$ & $\begin{array}{l}\text { How often engaged } \\
\text { in extramarital } \\
\text { sexual intercourse } \\
\text { during the past } \\
\text { year }\end{array}$ & $\begin{array}{l}0=\text { none, } 1=\text { once, } 2= \\
\text { twice, } 3=3 \text { times, } 7=4-10 \\
\text { times, } 12=\text { monthly, } 12= \\
\text { weekly, } 12=\text { daily }\end{array}$ & 1.46 \\
\hline $42 \ldots$ & $z_{1}$ & Sex & $0=$ female, $1=$ male & .476 \\
\hline $43 \ldots$ & $z_{2}$ & Age & $\begin{array}{l}17.5=\text { under } 20,22.0= \\
20-24,27.0=25-29,32.0= \\
30-34,37.0=35-39,42.0= \\
40-44,47.0=45-49,52.0= \\
50-54,57.0=55 \text { or over }\end{array}$ & 32.5 \\
\hline $47 \ldots$ & $z_{3}$ & $\begin{array}{l}\text { No. of years } \\
\text { married }\end{array}$ & $\begin{array}{l}.125=3 \text { months or less, } \\
417=4-6 \text { months, } .75= \\
6 \text { months }-1 \text { year, } 1.5=1-2 \\
\text { years, } 4.0=3-5 \text { years, } \\
7.0=6-8 \text { years, } 10.0=9-11 \\
\text { years, } 15.0=12 \text { or more } \\
\text { years }\end{array}$ & 8.18 \\
\hline $50 \ldots$ & $z_{4}$ & Children & $0=$ no, $1=$ yes & .715 \\
\hline $56 \ldots$ & $z_{5}$ & How religious & $\begin{array}{l}5=\text { very, } 4=\text { somewhat } \\
3=\text { slightly, } 2=\text { not at all, } \\
1=\text { anti }\end{array}$ & 3.12 \\
\hline $60 \ldots$ & $z_{6}$ & Level of education & $\begin{array}{l}9.0=\text { grade school, } 12.0= \\
\text { high school graduate, } 14.0= \\
\text { some college, } 16.0=\text { college } \\
\text { graduate, } 17.0=\text { some } \\
\text { graduate work, } 18.0=\text { master's } \\
\text { degree, } 20.0=\text { Ph.D., M.D., } \\
\text { or other advanced degree }\end{array}$ & 16.2 \\
\hline $64 \ldots$ & $z_{7}$ & Occupation & $\begin{array}{l}1-7 \text {, according to Hollingshead } \\
\text { classification (reverse } \\
\text { numbering) }\end{array}$ & 4.19 \\
\hline \multirow[t]{2}{*}{$66 \ldots$} & $z_{8}$ & How rate marriage & $\begin{array}{l}5=\text { very happy, } 4=\text { happier } \\
\text { than average, } 3=\text { average, } \\
2=\text { somewhat unhappy, } \\
1=\text { very unhappy }\end{array}$ & 3.93 \\
\hline & \multicolumn{4}{|c|}{$R B$ Tape } \\
\hline$\cdots$ & $y_{R B}$ & $\begin{array}{l}\text { Measure of time } \\
\text { spent in extra- } \\
\text { marital affairs } \\
(=.0 \text { or }= \\
\left.q_{1} q_{2} / \nu_{3}\right)\end{array}$ & $.0-57.6$ & .705 \\
\hline $49 \ldots$ & $q_{1}$ & $\begin{array}{l}\text { If since marriage } \\
\text { have had sexual } \\
\text { relations with man } \\
\text { other than husband, } \\
\text { with how many } \\
\text { different men }\end{array}$ & $\begin{array}{l}1.0=1,3.5=2-5,8.0= \\
6-10,12.0=\text { more than } 10\end{array}$ & $\ldots$ \\
\hline
\end{tabular}


TABLE 1 (Continued)

\begin{tabular}{|c|c|c|c|c|}
\hline $\begin{array}{l}\text { Question } \\
\text { No. }\end{array}$ & $\begin{array}{l}\text { Notation } \\
\text { for } \\
\text { Variable }\end{array}$ & $\begin{array}{l}\text { Description } \\
\text { of Variable }\end{array}$ & Values of Variable & $\begin{array}{l}\text { Mean } \\
\text { Value }\end{array}$ \\
\hline & \multicolumn{4}{|c|}{ RB Tape } \\
\hline $50 \ldots$ & $q_{2}$ & $\begin{array}{l}\text { Continuing from } \\
\text { question } 49, \\
\text { approximate } \\
\text { number of times } \\
\text { had sexual } \\
\text { relations with each } \\
\text { man }\end{array}$ & $\begin{array}{l}1.0=\text { once, } 3.5=2-5,8.0= \\
6-10,12.0=\text { more than } 10, \\
5.6=\text { it varied greatly from } \\
\text { partner to partner }\end{array}$ & $\cdots$ \\
\hline $2 \ldots$ & $v_{1}$ & How rate marriage & $\begin{array}{l}5=\text { very good, } 4=\text { good, } \\
3=\text { fair, } 2=\text { poor, } 1=\text { very } \\
\text { poor }\end{array}$ & 4.11 \\
\hline $61 \ldots$ & $v_{2}$ & Age & $\begin{array}{l}17.5=\text { under } 20,22.0=20- \\
24,27.0=25-29,32.0=30- \\
34,37.0=35-39,42.0=40 \\
\text { or over }\end{array}$ & 29.1 \\
\hline 63 & $v_{3}$ & No. years married & $\begin{array}{l}.5=\text { less than } 1 \text { year, } 2.5= \\
1.4 \text { years, } 6.0=5-7 \text { years, } \\
9.0=8-10 \text { years, } 13.0 \text { if more } \\
\text { than } 10 \text { years and oldest child } \\
\text { under } 12 \text { years of age, } 16.5 \text { if } \\
\text { more than } 10 \text { years and oldest } \\
\text { child between } 12 \text { and } 17 \text { years } \\
\text { of age, } 23.0 \text { if more than } 10 \\
\text { years and oldest child } 18 \text { years } \\
\text { of age or over }\end{array}$ & 9.01 \\
\hline $66 \ldots$ & $v_{4}$ & No, children & $\begin{array}{l}.0=\text { none, } 1.0=1,2.0=2 \\
3.0=3,4.0=4,5.5=5 \text { or } \\
\text { more }\end{array}$ & 1.40 \\
\hline $70 \ldots$ & $v_{5}$ & How religious & $\begin{array}{l}4=\text { strongly, } 3=\text { fairly } \\
2=\text { mildly, } 1=\text { not }\end{array}$ & 2.43 \\
\hline $72 \ldots$ & $v_{6}$ & Level of education & $\begin{array}{l}9.0=\text { grade school, } 12.0= \\
\text { high school, } 14.0=\text { some } \\
\text { college, } 16.0=\text { college } \\
\text { graduate, } 17.0=\text { some } \\
\text { graduate school, } 20.0= \\
\text { advanced degree }\end{array}$ & 14.2 \\
\hline $75 \ldots$ & $v_{7}$ & Occupation & $\begin{array}{l}6=\text { professional with advanced } \\
\text { degree, } 5=\text { managerial, } \\
\text { administrative, business, } 4= \\
\text { teacher, counselor, social } \\
\text { worker, nurse; artist, writer; } \\
\text { technician, skilled worker, } \\
3=\text { white-collar (sales, } \\
\text { clerical, secretarial), } 2= \\
\text { farming, agriculture; semi- } \\
\text { skilled or unskilled worker; } \\
\text { other, } 1 \text { = student }\end{array}$ & 3.42 \\
\hline $77 \ldots$ & $v_{8}$ & $\begin{array}{l}\text { Husband's } \\
\text { occupation }\end{array}$ & Same as $v_{7}$ & 3.85 \\
\hline
\end{tabular}


vations, and the size of the usable sample from the $R B$ tape was 6,366 observations.

Table 1 is self-explanatory, and only a few remarks about it will be presented here. In the column "Values of Variable" the items to the right of the equal signs are the answers that were allowed on the questionnaires. The number to the left of each equal sign is the value chosen by the author to represent that answer. A number of questions were open-ended in the upper range, and fairly arbitrary values for the largest value of the variables had to be used in these cases (see $z_{2}, z_{3}, v_{2}, v_{3}$, and $v_{4}$ ). The 5.6 value used for the last answer pertaining to $q_{2}$ is the average of values of the other answers weighted by the number of people who chose each answer.

The largest value of $y_{P T}$ was taken to be 12 , even though larger values could have been used for people who answered that they engaged in extramarital sexual intercourse weekly or daily. This means that $t_{2}$ was assumed to be the same for monthly, weekly, and daily people. As discussed below, a linear specification was used for the estimated equation, and it did not seem reasonable in this case, given the range of values of the explanatory variables, to have a dependent variable that ranged from, say, 0 to 365 .

The $R B$ questionnaire did not ask if the person was currently having an affair, and $y_{R B}$ as defined in table 1 was the best that could be done regarding a measure of $t_{2}$. The implicit assumption here in the use of $y_{R B}$ as a measure of $t_{2}$ is that the current value of $t_{2}$ is highly correlated with past values of $t_{2}$. The occupation variable $z_{3}$ was coded onto the tape according to the Hollingshead (1957) classification, a classification that is meant to correspond in at least some rough way to social position.

Table 1 includes all variables from the two tapes that appeared to be relevant for purposes of this study. ${ }^{4}$ Table 2 contains a matching of these variables with the variables from the theoretical model. The first half of table 2 contains a list of the explanatory variables in the theoretical model and their expected effects on $t_{2}$. The second half of the table contains a list of the observed explanatory variables, their likely correlation with the explanatory variables in the theoretical model, and their likely effects on the dependent variable. The following is a brief discussion of the second half of table 2.

The occupation variables $\left(v_{7}\right.$ and $z_{7}$ ) are likely to be positively correlated with the wage rate $(w)$. The correlation may not, however, be very large for $z_{7}$, since the Hollingshead classification used in the coding of the variable is more a classification by social position than it is by wage rate.

\footnotetext{
4 Both surveys included a question about the size of family income, but this variable is unfortunately of no use here. Family income is, among other things, a function of $t_{3}$, which is itself a decision variable $\left(t_{3}=T-t_{1}-t_{2}\right)$. It would be inappropriate to use as an explanatory variable for $t_{2}$ a variable that is directly related to $t_{3}$ in this way.
} 
TABLE 2

Matching of the Vartables in the Theoretical Model with Observed Variables A. TheORETICAL MODEL*

\begin{tabular}{|c|c|c|c|c|}
\hline \multicolumn{4}{|c|}{ Explanatory Variables } & Effect $c$ \\
\hline \multicolumn{4}{|c|}{ 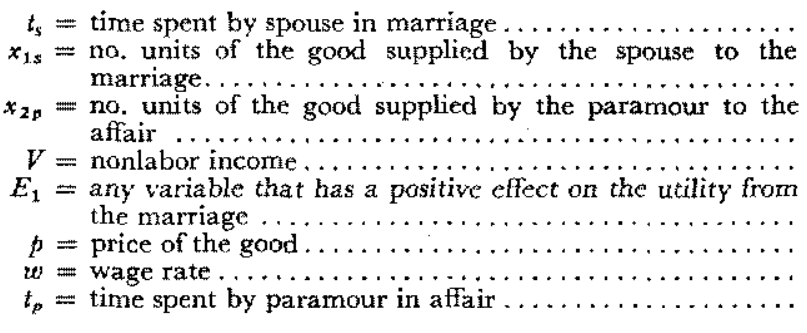 } & $\begin{array}{c}+ \\
+ \\
+ \\
\text { Ambiguous } \\
\text { Ambiguous } \\
\text { Ambiguous, but likely } \\
\text { to be }+\end{array}$ \\
\hline \multicolumn{5}{|c|}{ CAL WORK! } \\
\hline$\frac{\text { Orse } 1}{P T}$ & $R B$ & $\frac{R Y \text { VARIABLES }}{\text { Variable }}$ & $\begin{array}{r}\text { LIKELY } \\
\text { CoRRELAT } \\
\text { (SIC }\end{array}$ & $\begin{array}{l}\text { LiKELX EFFECT ON } \\
\text { DEPENDENT } \\
\text { VARIABLE }\end{array}$ \\
\hline $\begin{array}{l}z_{7} \ldots \\
z_{6} \cdots \cdots \\
\cdots \cdots \\
z_{8} \cdots \cdots \\
z_{2}\end{array} \ldots$ & $\begin{array}{l}v_{7} \\
v_{6} \\
v_{8} \\
v_{1} \\
v_{2}\end{array}$ & $\begin{array}{l}\text { Occupation } \\
\text { Education } \\
\text { Husband's occupation } \\
\text { Marital happiness } \\
\text { Age }\end{array}$ & $\begin{array}{c}w(+) \\
w(+) \\
x_{1 s}(+) \\
E_{1}(+) \\
E_{2}(-) \text { (or none) } \\
E_{1}(-) \text { (or none) } \\
E_{1}(+) \text { (or none) } \\
E_{2}(-)\end{array}$ & $\begin{array}{l}\text { Ambiguous } \\
\text { Ambiguous } \\
\text { Ambiguous, but likely } \\
\text { to be - (or none) } \\
+ \text { (or none) } \\
\quad \text { (or none) } \\
\text { Ambiguous, but likely } \\
\text { to be - } \\
\text { none }\end{array}$ \\
\hline
\end{tabular}

- Dependent variable: $t_{2}=$ time spent in affair.

$\dagger$ Observed dependent variables: $y_{P T}$ and $y_{R B}$ (see table 1).

Even if $z_{7}$ and $v_{7}$ are positively correlated with $w$, their effect on the dependent variables is ambiguous because the effect of $w$ on $t_{2}$ is ambiguous. The effect of the education variables $\left(z_{6}\right.$ and $\left.v_{6}\right)$ on the dependent variables is likewise ambiguous, even though $z_{6}$ and $v_{6}$ are likely to be positively correlated with $w$.

With respect to the husband's occupation variable $\left(v_{8}\right)$, to the extent that it is positively correlated with the husband's wage rate, it is likely to be positively correlated with $x_{1 s}$, the value of goods supplied by the husband to the marriage. The effect of $v_{B}$ on the dependent variable is thus expected to be positive.

The variables $z_{8}$ and $v_{1}$ measure marital happiness, which in the present context means that they are positively correlated with $E_{1}$. They are thus 
expected to have a negative effect on the dependent variables. These two variables are quite unusual and useful variables to have in a study of this kind. There are clearly many factors that have an effect on the utility from a marriage that are not observed, and variables like $z_{8}$ and $v_{1}$ are likely to capture the effects of a number of these factors.

If age has a negative effect on the enjoyment of sexual activity, something which may or may not be true, and if affairs are primarily sexual, then age will have a negative effect on the utility from an affair. The age variables $\left(z_{2}\right.$ and $\left.v_{2}\right)$ may thus be negatively correlated with $E_{2}$, in which case they are likely to have a negative effect on the dependent variables. If the number of years married has a negative effect on the utility from the marriage because of boredom, something which again may or may not be true, then the variables $z_{3}$ and $v_{3}$ will be negatively correlated with $E_{1}$ and will thus have a positive effect on the dependent variables. If the existence or number of children has a positive effect on the utility from the marriage because of time spent by the children in the household, then the variables $z_{4}$ and $v_{4}$ will be positively correlated with $E_{1}$ and will thus have a negative effect on the dependent variables.

The degree of religiosity of a person may have a negative effect on the utility from an affair to the extent that it is related to concerns about divine or moral disapprobations from engaging in an affair. The religious variables $z_{5}$ and $v_{5}$ may thus be negatively correlated with $E_{2}$, and if they are they are then likely to have a negative effect on the dependent variables. ${ }^{5}$ The last variable in table 2 , the sex of the person $\left(z_{1}\right)$, is not expected from the theoretical model to have any effect on $t_{2}$. No behavioral differences between men and women were postulated in the model; $i$ in Section II can be either a man or a woman.

This completes the discussion of table 2 . While it would be useful to have access to more data, the data from the two tapes do allow enough variables to be constructed to provide at least a rudimentary test of the model. The last item to be discussed in this section is the estimation technique used.

When the dependent variable $t_{2}$ is zero, the first-order conditions do not necessarily hold. Because of this and because many values of $y_{P T}$ and $y_{R B}$ are zero, it would clearly be incorrect to use ordinary least squares to estimate the equations. The obvious technique to use in this case is the Tobit estimator (Tobin 1958). Let $\bar{z}_{i}$ and $\bar{v}_{i}$ denote row vectors of observations on the explanatory variables for individual $i$ from the $P T$ and $R B$

${ }^{5}$ If, as discussed at the end of Section II, the person's decision problem were set up as a multiperiod optimization problem, the effects of concern about divine or moral disapprobations could be handled in a more explicit way. In this framework, the person could be considered as weighing the current utility from the affair against possible loss of utility in the future (perhaps in a future life) from divine or moral disapprobations. 
tapes, respectively. Let $\alpha$ and $\beta$ denote the corresponding column vectors of unknown coeflicients. The stochastic specification of the model is then :

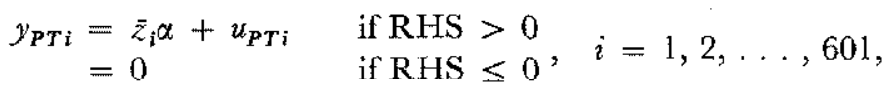

$$
\begin{aligned}
& \begin{aligned}
y_{R B i} & =\bar{v}_{i} \beta+u_{R B i} & & \text { if RHS }>0 \\
& =0 & & \text { if RHS } \leq 0
\end{aligned}, \quad i=1,2, \ldots, 6,366,
\end{aligned}
$$

where $u_{P T_{i}}$ and $u_{R B i}$ are independently distributed error terms with distributions $N\left(0, \sigma_{P T}^{2}\right)$ and $N\left(0, \sigma_{R B}^{2}\right)$, respectively (RHS = right-hand side). This specification is consistent with the theoretical model in the sense that the variables in $\bar{z}_{i}$ and $\bar{v}_{i}$ have an effect on $y_{P T i}$ and $y_{R B i}$ if the latter two are nonzero (no corner solutions), but not otherwise.

Tobit estimates are generally computed by some version of Newton's method, but with 6,366 observations this can be expensive. Tobit estimates can, however, as discussed in Fair (1977), be computed by a much simpler procedure, and this is the procedure that was used for the work in this study. Some initial experimentation indicated that considerable computer time could be saved by the use of this procedure over Newton's method.

\section{The Results}

The results of estimating equations (12a) and (12b) by the Tobit estimator are presented in table 3 . Two sets of coefficient estimates are presented for each equation. For the first set all of the $z_{j}$ or $v_{j}$ variables in table 1 were used as explanatory variables; for the second set some of these variables were excluded.

The $P T$ and $R B$ results are in fairly close agreement. Variables that are clearly significant ${ }^{6}$ are marital happiness $(-)$, age $(-)$, number of years married $(+)$, and degree of religiosity $(-)$. The signs of the coefficient estimates are as expected from table 2 . The sex dummy variable, $z_{1}$, is not significant, which is also as expected from the discussion in the previous section. The fact that the coefficient estimates of age and length of marriage are significantly negative and positive, respectively, is interpreted from the theory to mean that utility from affairs declines with age and that utility from marriage declines with length of marriage. The negative significance of the religiosity variable means from the theory that utility from affairs declines with the degree of religiosity of the person. Finally, the high negative significance of the marital happiness variable indicates that it is a good proxy for a number of unobserved factors that have an effect on the utility from marriage.

\footnotetext{
"In what follows a variable will be said to be "significant" if its $t$-statistic in table 3 is greater than 1.65 in absolute value, 1.65 being the critical value of the $t$ distribution with infinite degrees of freedom at the 95 percent confidence level for a one-tailed test.
} 
TABLE 3

The Results

\begin{tabular}{|c|c|c|c|c|c|c|c|c|c|c|}
\hline \multirow[b]{2}{*}{ Variable } & & \multicolumn{4}{|c|}{$P T \mathrm{DATA}^{*}$} & & \multicolumn{4}{|c|}{$R B \mathrm{D}_{\mathrm{AT \Lambda}} \dagger$} \\
\hline & & $\begin{array}{c}\text { Coeff. } \\
\text { Est. }\end{array}$ & $t$-Stat. & $\begin{array}{c}\text { Coeff. } \\
\text { Est. }\end{array}$ & $t$-Stat. & & $\begin{array}{c}\text { Coeff. } \\
\text { Est. }\end{array}$ & $i$-Stat. & $\begin{array}{c}\text { Coeff. } \\
\text { Est. }\end{array}$ & t-Sitat. \\
\hline 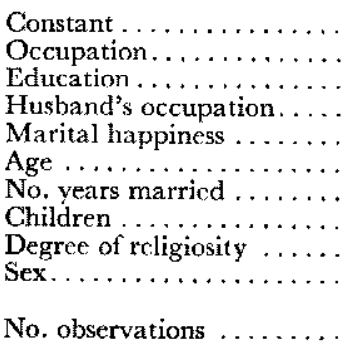 & $\begin{array}{l}\cdots \\
z_{7} \\
z_{6} \\
z_{8} \\
z_{2} \\
z_{3} \\
z_{4} \\
z_{5} \\
z_{1} \\
\hat{\sigma}_{P T}^{2}\end{array}$ & $\begin{array}{c}7.60 \\
.213 \\
.0252 \\
-2.27 \\
-.193 \\
.533 \\
1.02 \\
-1.70 \\
.945 \\
8.26 \\
6017\end{array}$ & $\begin{array}{r}1.92 \\
.67 \\
.11 \\
-.5 .48 \\
-2.37 \\
3.63 \\
.79 \\
-4.15 \\
.88 \\
\ldots\end{array}$ & $\begin{array}{c}8.17 \\
.326 \\
\cdots \\
\ldots \\
-2.28 \\
-.179 \\
.554 \\
-1.69 \\
. .25 \\
8.251 \%\end{array}$ & $\begin{array}{c}2.96 \\
1.29 \\
\cdots \\
-5.61 \\
-2.26 \\
4.13 \\
-4.14 \\
\cdots \\
\cdots\end{array}$ & $\begin{array}{l}\cdots \\
v_{7} \\
v_{6} \\
v_{8} \\
v_{1} \\
v_{2} \\
v_{3} \\
v_{4} \\
v_{5} \\
\ddot{\sigma}_{R B}^{2}\end{array}$ & $\begin{array}{c}7.85 \\
.314 \\
-.0853 \\
.0151 \\
-1.53 \\
-.107 \\
.130 \\
-.0285 \\
-.944 \\
\ldots . .50 \\
6,3668\end{array}$ & $\begin{array}{r}11.10 \\
3.77 \\
-2.24 \\
.27 \\
-20.68 \\
-4.24 \\
4.82 \\
-.36 \\
-11.03 \\
\ldots \\
\ldots\end{array}$ & $\begin{array}{c}7.18 \\
.255 \\
\ldots \\
-1.53 \\
-.120 \\
.110 \\
\ldots \\
-.950 \\
4.50 \\
6,366 \S\end{array}$ & $\begin{array}{c}11.39 \\
3.30 \\
\ldots \\
\ldots \\
-20.82 \\
-4.91 \\
6.11 \\
\ldots \\
-11.14 \\
\ldots \\
\ldots\end{array}$ \\
\hline
\end{tabular}

NoтE.- " $t$-Stat." = ratio of coefficient estimate to estimated standard error of coefficient estimate.

${ }^{*} y_{P T}$ is dependent variable.

$Y_{1} B$ is dependent variable.

2,053 nonzero. 
The results regarding the occupation and education variables are mixed. For the $P T$ results neither variable is significant. For the $R B$ results the estimates of the coefficients of the two variables are significant but of opposite signs, which is not as expected if both variables are positively correlated with the wage rate. The occupation variable had a higher $t$-statistic associated with it than did the education variable in each case in table 3, and so for the second set of estimates in each case the education variable was excluded from the equation. In both cases the sign of the estimate of the coefficient of the occupation variable is positive, which if the variable is a proxy for the wage rate implies from the analysis in Section II that the income effect of a change in the wage rate on the time spent in the affair is larger than the substitution effect. It is not clear, however, that much confidence should be placed on this result because of the overall mixed results regarding the occupation and education variables. It may be that neither variable is a good proxy for the wage rate.

For the $R B$ results, the estimate of the coefficient of the husband's occupation variable is of the expected positive sign, but it is not significant. It may also be that this variable is not a good proxy for the husband's wage rate (and thus for the value of goods supplied by the husband to the marriage), which would explain its lack of significance. For both the $P T$ and $R B$ results the children variable is insignificant. This means from the theory that children have no independent effect on the utility from the marriage. Any positive effects of children must be offset by a sufficient number of negative ones. This is not necessarily as expected, but it does seem to be what both the $P T$ and $R B$ data indicate.

\section{Conclusion}

The primary purpose of this paper has been to develop a model to explain the allocation of an individual's time among spouse, paramour, and work. The model can, however, be fairly easily applied to other types of leisure activities. The main motivation in this paper for considering leisure activities with more than one person is the same motivation that lies behind the postulation of more than one good in the utility function in classical demand theory, namely, that variety is important in life. Given this, it is of some interest to see if economic analysis can help explain the allocation of an individual's leisure time among various activities.

Although the data used in this study are far from ideal for testing the model as applied to extramarital affairs, the results in table 3 do lend some support to it. At the least, the results suggest that further tests of the model would be of interest. It is clear for any future tests of the model that better data on wage rates are needed. A better test of the model could also be performed if data on nonlabor income were available. 


\section{References}

Becker, Gary S. "Crime and Punishment: An Economic Approach." J.P.E. 76, no. 2 (March/April 1968): 169-217.

- "A Theory of Marriage: Part I." J.P.E. 81, no. 4 (July/August 1973): $813-46$.

Donne, John. "Elegie XVII. Variety." In John Donne: Poetry and Prose, edited by Frank J. Warnke. New York: Random House, 1967.

Fair, Ray C. "A Note on the Computation of the Tobit Estimator." Econometrica 45 (1977): 1723-27.

Hollingshead, August B. "Two-Factor Index of Social Position." Mimeographed. Yale Univ., 1957.

Kelley, Jonathan. "Sex and Social Bonds: A Theory." Mimeographed. Yale Unjv., 1976.

Tobin, James. "Estimation of Relationships for Limited Dependent Variables." Econometrica 26 (January 1958) : 24-36. 